\title{
Alluvial Gold Mining Sites as Exposure Pathways for Methyl Mercury Toxicity in Children: A Systematic Review
}

\author{
Rose K. Begani, Alphonse Z. Begani \\ Department of Environmental Health, Faculty of Medicine and Health Sciences, Divine Word University, Madang, Papua New \\ Guinea \\ Email: rbegani@dwu.ac.pg1, abegani@dwu.ac.pg2
}

How to cite this paper: Begani, R.K. and Begani, A.Z. (2017) Alluvial Gold Mining Sites as Exposure Pathways for Methyl Mercury Toxicity in Children: A Systematic Review. Health, 9, 930-941. https://doi.org/10.4236/health.2017.96066

Received: April 3, 2017

Accepted: June 17, 2017

Published: June 20, 2017

Copyright $\odot 2017$ by authors and Scientific Research Publishing Inc. This work is licensed under the Creative Commons Attribution International License (CC BY 4.0).

http://creativecommons.org/licenses/by/4.0/

(c) (i) Open Access

\begin{abstract}
Extensive studies have showed that alluvial gold mining is a predisposing factor for mercury toxicity through occupational exposure. In our systematic review of related literature, we aim to determine if children of alluvial gold miners were at risk of exposure to methyl mercury toxicity through dietary exposure. This was achieved through applying Cochrane PICO methodology for the research question. We selected only the most relevant articles from the thousands of articles that were generated by the Divine Word University (DWU) electronic data base system for our review. Further screening questions were applied based on the CASP method which filtered remaining 105 to only 9 papers for the review. The results from the nine $(\mathrm{N}=9)$ studies analysed showed convincing results of the association between consumption of fish contaminated with methyl mercury and poor growth and development in children whose parents lived near mining sites. We conclude that since mercury is the predominant element used in the extraction of gold in alluvial mining, it is an exposure pathway for methyl mercury toxicity for children through dietary exposure.
\end{abstract}

\section{Keywords}

Alluvial Gold Mining, Small Scale Mining, Methyl Mercury, Bulolo/Wau District, Toxicity

\section{Introduction}

Artisan and small scale mining (ASSM) are widely practiced in developing countries of the world and Papua New Guinea (PNG) is no exception. With the use of amalgamation as the extraction method, gold miners usually use mercury 
to separate the element from the alluvium ${ }^{1}$. The mercury is then cooked in containers releasing vaporized mercury into the atmosphere and surrounding environments ${ }^{2}$. Vaporised mercury can eventually ends up in the soil and river systems through natural elements such as the hydrological cycle whereby it is converted into methyl mercury thus contaminating fish predominantly ${ }^{3}$. Within the Wau and Bulolo area of Morobe province in PNG this is a normal practice and although ASSM has been in PNG for decades ${ }^{4}$; no assessments have been done to assess the risks to human health either from dietary exposure or environmental exposure to organic mercury.

The study of organic mercury is of significant public health concern because of its tendency to remain in the environmental media and be converted by methyl bacteria into methyl mercury which can consequently affect humans ${ }^{5}$. Moreover, the element has the capacity to bio accumulate in aquatic organisms such as fish and shell fish hence the larger the organisms are, the higher the bio magnification levels in these organisms ${ }^{6}$ are. Since these organisms provide a source of dietary protein to humans, it then becomes a public health issue because of the effects of methyl mercury on the nervous systems and neurological systems of humans. The effects of methyl mercury on human population can vary but a number of studies have pointed out the vulnerable groups to be pregnant women and children ${ }^{7}$.

Pregnant mothers and infants are particularly vulnerable to methyl mercury toxicity as it has the potential to cross the blood brain and placental barriers causing damage to neurological and nervous systems ${ }^{8}$. With the ingestion route, methyl mercury combines with cysteine, an amino acid, to form a methyl mercury conjugate which can pass through the blood brain barrier and placental barrier via a neutral amino acid carrier protein ${ }^{9}$. As the neurotoxicant penetrates the placental barrier, it reaches the fetus and can accumulate in the fetal brain due to its tendency to cross the blood brain barrier. Studies have clearly pointed out that the higher the amount of contaminated fish consumed by pregnant women the higher the level of $\mathrm{MeHg}$ were found in cord blood and hair samples of those studied indicating higher body burden of contamination in children ${ }^{10}$. Evidence has been so conclusive that the Food and Drug Administration (FDA) have recommended that mothers avoid certain fish during pregnancy to avert

\footnotetext{
${ }^{1}$ Aryee BNA N.B and Atorku E (2003).

${ }^{2}$ Reto C (2002).

${ }^{3}$ Ouboter E Paul, L. A. G., Quik M H Jan, Mol A H Jan, and Van der Lugt Frank (2012).

${ }^{4}$ Moretti D (2007).

${ }^{5}$ Grandjean Philippe, W. R. F., Nielsen Anne, Cleary David, and de Oliveira Santos Elizabeth C. (1999).

${ }^{6}$ Charles Elias, T. D. S., Dewey Deborah, Davey Mark, Ngallaba Sospatro E, and Konje Evelin (2013).

${ }^{7}$ Oken Emily, W. O. R., Kleinman P Ken, Bellinger David, Amarasiriwardena J Chitra, Hu Howard, Rich-Edwards W Janet, and Gillman W Mathew (2005).

${ }^{8}$ Gibb Herman, a. O. L. K. G. (2014).

${ }^{9}$ Konig A., B., C., Cohen, J. T., Connor, W. E., Etherton, P. M., Gray, G. M., Lawrence, R. S., Sawizt, D. A., and Teutsch, S. M. (2005).

${ }^{10}$ McDowell Margaret A., D. C. F., Osterloh John, Bolger P. Michael, Pellizzari Edo, Fernando Reshan, Montes de Oca Ruben, Schober Susan E., Sinks Thomas, Jones Robert L., and Mahaffey Kathryn R. (2004).
} 
deleterious effects on children such as low cognitive functions. Our evaluation on the current literature basing on nine (9) cohort studies and one (1) review supports this evidence which shows that the risk may be attributed to different exposure pathways such as mining and even alluvial gold mining because the predominant element used in the extraction of gold is mercury.

\section{Methodology}

\subsection{Description of the Systematic Literature Review}

Cochrane PICO method was used to develop the systematic review research question. The research question was structured using only "P" and "O" from PICO because the study will be related on the population of interest and its outcome with regard to methyl mercury exposure. This is also necessary because the research will be conducted in Papua New Guinea where the Country is disadvantaged with accredited laboratory to conduct intervention studies.

\subsection{Methods Applied in the Literature Review}

After the research question was formulated a search was conducted using Divine Word University (DWU) Library electronic data base. The search was conducted on the 27th, 28th and 29th of October 2014 and the 2nd lot of search was conducted on the 3rd, 4th and 5th of November 2014 using Google scholar, Cochrane, and JSTOR electronic data bases.

The keywords used in this order include health Impact of mercury on children neurodevelopment; mercury fish consumption, and child neurodevelopment methyl mercury exposure through fish consumption. This resulted in $4140 \mathrm{pa}-$ pers in Google Scholar electronic data base. The same keyword search was entered into Cochrane electronic data base which generated 818236 papers while 61948 papers were generated in JSTOR electronic data base.

The thousands of articles generated following the first search were scrutinized and eliminated based on the following requirements. That the papers selected must be full text, available online, peer reviewed, written in English language and published within 1998-2014. The purpose of choosing articles from 1998-2014 is to gather latest evidence available with regard to methyl mercury exposure and toxicity among children population.

The selected papers were based on the likely neurotoxicity effects on children particularly during prenatal and postnatal period of exposure to methyl mercury. The inclusion of the 9 studies was focused on pregnant mothers that were exposed through dietary consumption of mercury contaminated fish. Although the pregnant mothers were exposed directly to mercury their unborn babies were exposed indirectly through umbilical cord pathway as documented in the 9 studies. The other indirect exposure pathway is through breast feeding and through mothers that were exposed to dental filling with elemental mercury as documented by Daniels et al. 2004. It is not established from the 9 studies if corrections factors were applied to their results to correct for $\mathrm{MeHg}$ exposure.

Furthermore, papers that were excluded include newspapers, reviews, letters, 
and papers that do not have keyword search terms. In addition, the contents of the papers were browsed and eliminated when they were not related to the research question.

Finally, only original articles were included while secondary articles were removed. The scrutiny of the papers resulted with a total of 105 articles from the electronic data bases.

The remaining 105 articles were screened further using CASP method so that only articles that fulfilled the research question and of high quality were selected.

This quality control mechanism is necessary so that the research findings of the chosen papers are valid with statistically significant results. Only one out of the 9 papers by Davidson et al. 1998 reported in their methodology about PCBs in serum samples that were analyzed. These chemicals produce end points similarly to Methyl mercury, however, from their multiple regression test Davidson et al. 1998 noted no detectable PCBs in the blood serum samples of the test subjects. Furthermore, confounding factors such as PCBs, DDT, persistent organochlorine compounds, including dibenzofurans and dioxins metabolites were observed in North Atlantic in the fatty tissues of marine mammals believed to affect children but it was difficult to determine selective toxicological impacts of individual compounds.

Moreover, only Davidson et al. 1998 stated MeHg levels in prenatal and postnatal test subjects to be between 5 - 15 ppm of MeHg concentration on average. These measurements of $\mathrm{MeHg}$ concentration is within WHO guidelines of 50 ppm for Adults as a reference point. The WHO applied a safety factor of 10 to cover risks to the most sensitive sub group of the population assumed to be those prenatally exposed to $\mathrm{MeHg}$.

\section{Results}

From the selected papers $(\mathrm{N}=105)$ further screening was done to select the most appropriate papers through the use of filtering questions.

The filtering questions were grouped according to the results of the study being credible Table 1, and reproducible and beneficial as indicated in Table 2. A score of 0 to 1 was assigned to each of the article based on the filtering questions asked with a score of 0 indicating "no relevance", 0.5 indicating "unsure" and 1 indicating "Yes" (there is relevance in the study) as shown in Table 3. Based on the filtering questions only nine $(\mathrm{N}=9)$ papers were selected for our review with their total scores as shown in Figure 1.

\subsection{Credibility of the Study}

As shown in Table 1 eight $(\mathrm{N}=8)$ questions were ask on the objectives of the study, the methodology used, including the study design and sample size, and if there were any limitations including biases and measurement errors.

\subsection{Significance and Benefits of the Study}

Table 2 indicates that six $(\mathrm{N}=6)$ questions guided the researchers in their 
Table 1. Showing the questions asked based on the credibility of the study.

\section{IS IT A TRUST WORTHY STUDY?}

1. Was the objective of the study explicitly explained?

2. Were indicators/interventions explicitly described?

3. Is the research design relevant for human toxicity studies?

4. Is the sample size and sample reflective of the population?

5. Are confounding variables stated in the study that may affect the results?

6. Was pathogenesis described clearly in the study?

7. Was etiology and prognosis clearly described in the study?

8. Was objective measurement conducted to minimize bias?

Table 2. Showing the questions asked based on the significance and benefits of the study.

2. ARE THE RESULTS OF THE STUDY SIGNIFICANT AND WILL THEIR OUTCOME BE BENEFICIAL TO THE SOCIETY?

9. Are the tests results reproduce able in the next experiment?

10. Are the results statistically significant?

11. Are the test results relevant to human exposure?

12. Will the results contribute to new knowledge of methyl mercury toxicity studies?

13. Will the results assist in mitigating methyl mercury hazard and risks within workplace setting?

14. Are the results conclusive?

Table 3. Showing the questions asked based on fourteen (14) filtering questions and their relevance to our study, using a scale of 0 to 1 .

\begin{tabular}{|c|c|c|c|c|c|c|c|c|c|c|c|c|c|c|}
\hline \multirow{3}{*}{$\begin{array}{l}\text { Journals } \\
\text { Articles }\end{array}$} & \multicolumn{14}{|c|}{ CASP Screening questions $(1-14)$ with assigned values } \\
\hline & \multicolumn{14}{|c|}{$0=$ No Relevance; $0.5=$ Unsure; $1=$ Yes, there is relevance } \\
\hline & 1 & 2 & 3 & 4 & 5 & 6 & 7 & 8 & 9 & 10 & 11 & 12 & 13 & 14 \\
\hline $\begin{array}{l}\text { Davidson } \\
\text { et al., } 1998\end{array}$ & 1 & 0.5 & 1 & 0.5 & 0.5 & 0.5 & 0.5 & 1 & 1 & 0.5 & 1 & 1 & 1 & 1 \\
\hline $\begin{array}{l}\text { Wijngaarden } \\
\text { et al., } 2013\end{array}$ & 0.5 & 1 & 1 & 0.5 & 1 & 0.5 & 0.5 & 0.5 & 1 & 0.5 & 1 & 1 & 1 & 0.5 \\
\hline $\begin{array}{l}\text { Oken } \\
\text { et al., } 2005\end{array}$ & 1 & 1 & 1 & 0.5 & 0.5 & 0.5 & 1 & 0.5 & 1 & 0 & 1 & 1 & 1 & 0 \\
\hline $\begin{array}{l}\text { Daniels } \\
\text { et al., } 2004\end{array}$ & 0.5 & 0.5 & 0.5 & 0.5 & 1 & 1 & 1 & 0 & 0.5 & 0.5 & 1 & 1 & 1 & 0.5 \\
\hline $\begin{array}{l}\text { Davidson } \\
\text { et al., } 2006\end{array}$ & 0.5 & 0 & 1 & 0.5 & 0.5 & 0.5 & 0.5 & 1 & 1 & 1 & 1 & 1 & 1 & 1 \\
\hline $\begin{array}{l}\text { Davidson } \\
\text { et al., } 2008\end{array}$ & 0.5 & 0.5 & 1 & 1 & 1 & 0.5 & 0.5 & 0.5 & 1 & 1 & 1 & 1 & 1 & 0.5 \\
\hline $\begin{array}{l}\text { Lederman } \\
\text { et al., } 2008\end{array}$ & 1 & 0.5 & 1 & 0.5 & 0 & 0.5 & 0.5 & 0.5 & 1 & 0.5 & 1 & 1 & 1 & 1 \\
\hline $\begin{array}{l}\text { Jedrychowski } \\
\text { et al., } 2007\end{array}$ & 1 & 0.5 & 0.5 & 0.5 & 1 & 0.5 & 0.5 & 0.5 & 1 & 1 & 1 & 1 & 1 & 1 \\
\hline $\begin{array}{l}\text { Yorifuji } \\
\text { et al., } 2011\end{array}$ & 1 & 1 & 0.5 & 0.5 & 1 & 1 & 1 & 0.5 & 0.5 & 0.5 & 1 & 1 & 1 & 0.5 \\
\hline
\end{tabular}




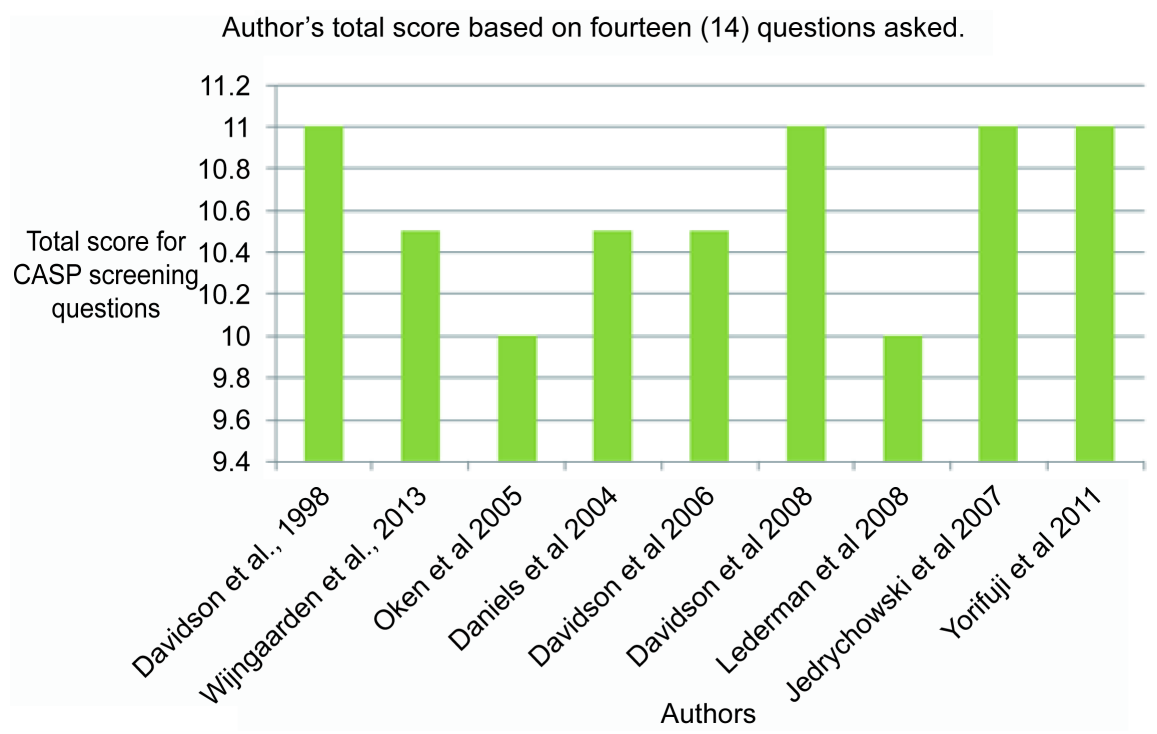

Figure 1. Shows the author's total score based on CASP screening questions.

selection of the articles based on whether the experiments conducted were reproducible and whether the results of the studies proved significant and beneficial to the society.

\subsection{Assigning Scores for Selecting the Most Relevant and Significant Paper}

As shown in Table 3 nine $(\mathrm{N}=9)$ papers were screened based on the fourteen filtering questions asked and were each given a score of 0 to 1 to determine their overall score.

\subsection{Author's Total Scores Based on the Fourteen Filtering Questions Asked}

As shown in Figure 1 Four $(\mathrm{N}=4)$ of the papers reviewed had the highest score of eleven (11) out of 14 questions, three $(\mathrm{N}=3)$ of the papers had a higher score of 10.5 out of 14 questions and two $(\mathrm{N}=2)$ papers had a high score of 10 out of 14 questions meeting the quality screening test using the CASP method to be selected for our review.

\section{Discussion}

The discussion will include general discussion of the articles considered in the review followed by their outcomes and the knowledge gaps within the 9 studies in general. The discussion will also make reference to World Health Organisation's (WHO) methyl mercury exposure recommendations in light of the data presented in the 9 studies with concluding remarks.

\subsection{General Discussion}

The systematic literature review with reference to Cochrane recommendation has produced nine (9) articles which were of high quality for discussion. The 
successive discussion below will be concentrated on the condensed findings of the nine (9) articles as presented in Tables 1-3 on p. 4 - 5.

The nine (9) articles were based on cohort study designs looking at subjects that were exposed to various forms of mercury particularly methyl mercury and the likely pathogenesis and etiological outcome associated with methyl mercury exposure. The cohort design studies in this review include specifically prospective and retrospective cohort designs.

Retrospective cohort studies look at the medical records of subjects that were exposed and non-exposed to methyl mercury in the context of this review and predicting the disease outcome based on the relative risk factor associated with the exposure. Retrospective cohort study does not involve case follow studies like prospective based study designs.

Prospective cohort study design on the contrary requires identifying two groups of subjects that were exposed and non-exposed to methyl mercury from the start of the research and following up over a longer period of time to see the disease outcome within the two groups. It is worth noting that each study design will have room for biasness particularly the retrospective cohort design studies. Moreover, the nine (9) papers did not have intervention methods to assess the toxicity associated with methyl mercury exposure as observed. From the 9 studies 6 were prospective cohort design studies while the 3 were around retrospective design.

There is disagreement in the findings from the 9 papers because of the difference in their study designs, methodology, objectives, type of sample chosen, sample size, and the type of end points the researchers anticipated to achieve. It was, however, established in all the 9 studies that fish; umbilical cord tissue; maternal blood; and hair samples from the pregnant mothers and their children were employed as biomarkers to measure the concentration of $\mathrm{MeHg}$ in the participants.

The 9 nine studies, estimated the concentration of mercury levels indirectly from the hair samples from the participants; tissue from umbilical cord; and MeHg in the blood. For instance, the study by Davidson et al. 1998 found out that the Total Hg in hair samples of pregnant mother's correlates well with blood levels of MeHg. Mean maternal total $\mathrm{Hg}$ in hair was $6.8 \mathrm{ppm}$ and the mean child hair $\mathrm{Hg}$ total at age 66 months was $6.5 \mathrm{ppm}$. It was also estimated that the average prenatal $\mathrm{MeHg}$ exposure of $5.9 \mathrm{ppm}$ in maternal hair was found in mothers who consumed an average of $537 \mathrm{~g}$ of fish per week in the study by Davidson et al. 2008. The study by Oken et al. 2005 observed $0.55 \mathrm{ppm}$ as the mean maternal hair mercury in the study participants while the study by Winjgaarden et al. 2013 observed $6.9 \mathrm{ppm}$ mean $\mathrm{MeHg}$ for prenatal and $10.3 \mathrm{ppm}$ mean $\mathrm{MeHg}$ for postnatal exposure. There is strong association of $\mathrm{MeHg}$ concentration in the blood or hair samples with the amount of fish consumed in the 9 studies which is dose- response related. The MeHg levels vary across the 9 studies due to their study design, sample size, methodology, objectives, and endpoints as deliberated earlier. 
End points in the context of this review refer to neurological development status of subjects that were exposed to methyl mercury as the primary aim of the nine (9) studies. Although there were other end points stated in the nine articles the overall objective of this review was to observe if exposure to methyl mercury will impair neurological function in prenatal and postnatal subjects. The primary health end points that were documented in the 9 studies include child behaviours; cognitive function; and neurological defect as negative outcomes, however, a number of these studies have found out that high consumption of fish during pregnancy demonstrated positive health outcome such as better infant cognition. It was also documented by Oken et al. (2005) that higher MeHg concentration were associated with lower cognition level. This however should be treated with caution because the presence of Selenium in fish as a confounder which can have biological benefits as a MeHg detoxifying agent but was not discussed in the 9 studies.

Moreover, the research question and the objectives of the selected papers did not have clearly structured research questions which were a challenge in this review.

\subsection{Study Outcome(s)}

The six (6) prospective and the three (3) retrospective studies generally showed similarity in methyl mercury exposure and neurological development status among prenatal and postnatal subjects. There is, however, a controversial finding in one retrospective study to a prospective study. For instance the Prospective study by Davidson et al. 1998 on the effects of prenatal and postnatal methyl mercury exposure from fish consumption showed no serious effects on neurological development in prenatal and postnatal subjects 66 months later after methyl mercury exposure in the Seychelles study ${ }^{11}$. A retrospective study by Lederman et al. (2008) on the contrary showed possible neurological development impairment during fetal and child development at 36 and 48 months after consumption of fish by pregnant mothers ${ }^{12}$. These conflicting results can be attributed to the focus of their studies with possible confounders such as nutritional benefits of fish rather than adverse effects of contaminated fish for instance in the study by Davidson et al. 2008 compared to Lederman et al. (2008).

Interestingly, Yorifuji Takashi (2011) found convincing result that methyl mercury does indeed impairs intelligence in adult subjects in the Minamata area after chronic exposure to the neurotoxicant indicating strong negative association through occupational exposure ${ }^{13}$. This supports the existing scientific body of knowledge that $\mathrm{MeHg}$ is indeed a neurotoxicant apart from being a teratogen hence affect both adults and children that are exposed to the element near min-

\footnotetext{
${ }^{11}$ Davidson W Philip, M. J. G., Cox Christopher, Axtell Catherine, Shamlaye Conrad, Sloane-Reeves Jean, Cernichiari Elsa, Needham Larry, Choi Anna, Wang Yining, Berlin Maths, and Clarkson W Thomas (1998).

${ }^{12}$ Lederman Ann Sally, J. L. R., Caldwell L Kathleen, Rauh Virginia, Sheets E Stephen, Tang Deliang, ${ }^{13}$ Viswanathan Sheila, Becker Mark, Stein L Janet, Wang Y Richard, and Perera P Frederica (2008).

Yorifuji Takashi, T. T., Inoue Sachiko, Takao Soshi and Harada Masazumi (2011).
} 
ing/industrial sites that uses it.

It was also noted that consumption of methyl mercury contaminated fish was higher in areas within mining areas using a lot of the element leading to detrimental effects on the development and growth of children. Moreover, alluvial gold mining activities which are secondary to the main mining activities are sources of methyl mercury exposure. Children who accompany their parents to extract mineral of interests using mercury as an amalgam to retrieve gold for example during alluvial mining can be exposed to toxic mercury vapour. This is particularly true in the process of roasting the ore to retrieve mineral of interest such as gold. The other source of elemental mercury exposure as described by Daniels et al. 2004 includes maternal dental treatment during pregnancy. Although mercury is ubiquitous in the environment the authors of the nine (9) studies did not state the mercury levels in the ambient environment. In addition, the levels of mercury concentration in the fish flesh were not documented directly because of the methodology employed by the 9 studies. The method involved questionnaires administered to the mothers and their children to estimate the quantity of the ocean fish consumed and the frequency of consumption per week.

\subsection{Knowledge Gaps in the Existing Studies}

It is worth noting that from the nine (9) papers that were selected only the study by Davidson et al. 2008 indicated sample of 250 subjects which reflect $80 \%$ power to detect a difference of 5 between low and high MeHg groups using a two tailed test with a reference significance level of $\mathrm{p}<0.05$. Their study is notable in this regard because their research findings may reflect the population under study.

The remaining eight (8) of the papers on the contrary did not state the statistical power to verify the integrity of the sample sizes selected for their study. Statistical power is necessary to demonstrate if the selected samples in the 8 studies are representative of the population under study. Moreover, the population size from which the sample was taken was not stated in the 8 articles so that statistical power can be calculated for verification purpose. Finally, the studies did not provide conclusive findings for postnatal exposure of $\mathrm{MeHg}$ therefore further research would be required. This is particularly for children who live with their parents near small scale mining areas to determine the risks through dietary and occupational exposure.

This is because sometimes children tend to be involved in such activities or required by their parents to do small scale mining rather than attend school as is the case in PNG. In addition, the 9 studies did not make reference to other similar studies for the purpose of replication for comparison to demonstrate reliability of the laboratory tests that were done. Moreover, the studies did not document in their methodology and end points of $\mathrm{MeHg}$ toxicity that is certified by a neurologists or toxicologists relating to the signs and symptoms of the studied subjects. This is because other confounders such as PCBs, Selenium, and Orga- 
nophosphate compounds such as DDT can generate negative end points that are similar to MeHg toxicity. Similarly, there was no comparison made on the methods applied for health assessment in the studies. This is an important process to ensure the study results can be repeated to measure the reliability and validity of the experiments.

The use of Forest plot in our meta-analysis to evaluate the results of the 9 studies to demonstrate statistical significance, and the association of $\mathrm{MeHg}$ exposure and possible end points of cognitive deficits; behavior; and neurological development defect was a limitation in our review. However, based on narrative assessment most of the studies generated their results to be within the $95 \%$ confidence level, which can be significant.

\subsection{WHO Guideline Values for Methyl Mercury in Edible Fish}

According to World Health Organisation (WHO) and Food and Agriculture Organisation (FAO) (2008) $1.6 \mu \mathrm{g} / \mathrm{kg}$ is the Provisional Tolerable Weekly Intake (PTWI) to protect developing fetus and embryo from neurotoxic effect based on the Faroe and Seychelles Island studies on methyl mercury exposure (WHO 2004 cited in WHO 2008) $)^{14}$. The nine (9) studies have documented the results of methyl mercury exposure in ppm, however, the studies did not clearly state the mean concentration of $\mathrm{MeHg}$ in some fish samples so as to provide for calculations of risk that participants may be exposed to.

For instance, the study by Davidson et al. 2008 stated an average of 537gram of fish (nine meals containing fish) per week while the average prenatal $\mathrm{MeHg}$ exposure was $5.9 \mathrm{ppm}$ in maternal hair however there was a lack of $\mathrm{MeHg}$ concentration from some representative fish samples to allow risk evaluation against the WHO/FAO guidelines.

For instance, if $5.9 \mathrm{ppm}$ was present in the 537 gram of fish rather than maternal hair, how much $\mathrm{MeHg}$ is present in $537 \mathrm{~g}$ of fish? Therefore $0.537 \mathrm{~g} / \mathrm{Kg}=$ $0.573 \mathrm{~kg} \times 5.9=3.3807 \mathrm{mg}=3380 \mu \mathrm{g} \mathrm{MeHg}$. This assumption showed concentration of $\mathrm{MeHg}$ to be approximately 1000 times higher than the set $\mathrm{MeHg}$ value of $1.6 \mu \mathrm{g} / \mathrm{kg} /$ week as set by WHO and FAO. Nevertheless, this calculation supports the conclusion by Davidson et al. (2008) who found adverse association between MeHg and the mean Psychomotor Developmental Index (PDI) in exposed children.

\section{Conclusions}

Almost all of the studies evaluated have shown convincing results with a few exceptions of ones that have some conflicting results. This may have resulted from non-inclusion of statistical power to reflect the appropriate sample size for the studies indicating limitation in the research methodology. Similarly, results from postnatal exposure studies have shown to be inconclusive requiring further research as highlighted.

Fundamentally, the studies have highlighted well the association between

${ }^{14}$ World Health Organisation (2008). 
consumption of fish contaminated with high levels of methyl mercury and the associated health risk while there is a lack of the other significant exposure pathways apart from mining and food (fish). Nevertheless, we can conclude that alluvial gold mining is strongly associated with contamination of water bodies and as such consumption of fish from such contaminated sites will continue to place children's health at risk of mercury toxicity leading to poor growth and cognitive functions.

\section{References}

[1] Aryee, B.N.A., Ntibery, B.K. and Atorkui, E (2003). Trends in the Small-Scale Mining of Precious Metals in Ghana: A Perspective on Its Environmental Impacts. Journal of Clear Production, 11, 131-140. https://doi.org/10.1016/S0959-6526(02)00043-4

[2] Moretti, D. (2007) Artisanal and Small Scale-Mining in Asia Pacific. Case Study Series.

[3] Ouboter, P.E., Landburg, G.A., Quik, J.H.M., Mol, J.H.A. and van der Lugt, F. (2012) Mercury Levels in Pristine and Gold Mining Impacted Aquatic Ecosystems Suriname, South America. Royal Swedish Academy of Sciences, 41, 873-882. https://doi.org/10.1007/s13280-012-0299-9

[4] Reto, C. (2002) Possible Mercury Poisoning in Alluvial Gold Miners in the Pogera Valley, Papua New Guinea. Journal of Rural and Remote Environmental Health, 1, 10-12.

[5] Grandjean, P., White, R.F., Nielsen, A., Cleary, D. and de Oliveira Santos E.C. (1999) Methyl Mercury Neurotoxicity in Amazonian Children Downstream from Gold Mining. Environmental Health Perspectives, 107, 587-591. https://doi.org/10.1289/ehp.99107587

[6] Charles, E., Thomas, D.S.K., Dewey, D., Davey, M., Ngallaba, S.E. and Evelin, K. (2013) A Cross-Sectional Survey on Knowledge and Perceptions of Health Risks Associated with Arsenic and Mercury Contamination from Artisanal Gold Mining in Tanzania. BMC Public Health, 13, 1-8. https://doi.org/10.1186/1471-2458-13-74

[7] Oken Emily, Wright, O.R., Kleinman, K.P., Bellinger, D., Amarasiriwardena, J.C., $\mathrm{Hu}, \mathrm{H}$. , Rich-Edwards, J.W. and Gillman, M.W. (2005) Maternal Fish Consumption, Hair Mercury, and Infant Cognition in a U.S. Cohort. Environmental Health Perspectives, 113, 1376-1380. https://doi.org/10.1289/ehp.8041

[8] Gibb, H. and O'Leary, K.G. (2014) Mercury Exposure and Health Impacts among Individuals in the Artisanal and Small-Scale Gold Mining Community: A Comprehensive Review. Environmental Health Perspectives, 122, 667-672.

https://doi.org/10.1289/ehp.1307864

[9] Konig, A., Bouzan, C., Cohen, J.T., Connor, W.E., Kris-Etherton, P.M., Gray, G.M., Lawrence, R.S., Sawizt, D.A., and Teutsch, S.M. (2005) A Quantitative Analysis Fish Consumption and Coronary Heart Disease Mortality. American Journal of Preventative Medicine, 29, 335-345. https://doi.org/10.1016/j.amepre.2005.07.001

[10] McDowell, M.A., Dillon, C.F., Osterloh, J., Bolger, P.M., Pellizzari, E., Fernando, R., de Oca, R.M., Schober, S.E., Sinks, T., Jones, R.L. and Mahaffey K.R. (2004) Hair Mercury Levels in U.S. Children and Women of Childbearing Age: Reference Range Data from NHANES 1999-2000. Environmental Health Perspectives, 112, 11651171. https://doi.org/10.1289/ehp.7046

[11] Davidson, P.W., et al. (1998) Effects of Prenatal and Postnatal Methylmercury Ex- 
posure from Fish Consumption on Neurodevelopment: Outcomes at 66 Months of Age in the Seychelles Child Development Study. The Journal of the American Medical Association, 280, 701-707.

https://doi.org/10.1001/jama.280.8.701

[12] Lederman, S.A., Jones, R.L., Caldwell, K.L., Rauh, V., Sheets, S.E, Tang, D.L., Viswanathan, S., Becker, M., Stein, J.L., Wang, R.Y. and Perera, F.P. (2008) Relation between Cord Blood Mercury Levels and Early Child Development in a World Trade Center Cohort. Environmental Health Perspectives, 116, 1085-1091. https://doi.org/10.1289/ehp.10831

[13] Yorifuji, T., Tsuda, T., Inoue, S., Takao, S. and Harada, M. (2011) Long-Term Exposure to Methyl Mercury and Psychiatric Symptoms in Residents of Minamata, Japan. Environment International, 37, 907-913.

https://doi.org/10.1016/j.envint.2011.03.008

[14] World Health Organization (2008) Guidance for Identifying Populations at Risk from Mercury Exposure.

http://www.who.int/foodsafety/publications/chem/mercuryexposure.pdf

\section{Submit or recommend next manuscript to SCIRP and we will provide best} service for you:

Accepting pre-submission inquiries through Email, Facebook, LinkedIn, Twitter, etc. A wide selection of journals (inclusive of 9 subjects, more than 200 journals)

Providing 24-hour high-quality service

User-friendly online submission system

Fair and swift peer-review system

Efficient typesetting and proofreading procedure

Display of the result of downloads and visits, as well as the number of cited articles

Maximum dissemination of your research work

Submit your manuscript at: http://papersubmission.scirp.org/

Or contact health@scirp.org 